Article

\title{
An Experimental Comparison of the Effects of Nanocrystalline Core Geometry on the Performance and Dispersion Inductance of the MFTs Applied in DC-DC Converters
}

\author{
Dante Ruiz-Robles*(D), Carlos Figueroa-Barrera, Edgar L. Moreno-Goytia and \\ Vicente Venegas-Rebollar \\ Graduate Program and Research in Electrical Engineering (PGIIE), Instituto Tecnológico de Morelia, \\ Morelia 58120, Mexico; m11121332@morelia.tecnm.mx (C.F.-B.); elmoreno@itmorelia.edu.mx (E.L.M.-G.); \\ vvenegasr@itmorelia.edu.mx (V.V.-R.) \\ * Correspondence: dante@tecmor.mx; Tel.: +52-443-221-3177
}

Received: 8 February 2020; Accepted: 6 March 2020; Published: 7 March 2020

check for updates

\begin{abstract}
The development of Medium Frequency Transformers (MFTs) from a novel perspective is essential for the advancement of today's various relevant applications such as the emerging solid-state transformers, along with interfaces for the interconnection of photovoltaic parks and electric vehicles. The analysis, design and implementation of MFTs pursuing the achievement of characteristics such as high power density, high efficiency, and a specific dispersion inductance is a key goal for designers. There are several parameters and design methods that influence the final performance of an MFT, such as the geometry and material of the core. The advantages/disadvantages of each material/geometry combination, about the dispersion inductance for instance, are not well known, even considering a single material but various geometries. This paper presents the analysis, design and experimental development of three nanocrystalline-core MFTs, each one with a different core geometry (toroidal, type CC and shell-type). The purpose of this work is to evaluate and compare the most favourable characteristics and performance of each type of geometry, tested at $5 \mathrm{kHz}$ and $1.75 \mathrm{kVA}$. The cases studied, in simulation and experimentation with scaled prototypes, focus on evaluating the power density, the core losses, the winding losses, the geometric dimensions, and the dispersion inductance obtained in each MFT, as well as its performances operating with sinusoidal and square waveforms. The results show that: 1) the toroid core has higher efficiency; 2) the shell core has the lowest dispersion inductance and is easier to build, and 3) the CC type has the highest dispersion inductance. This new information is a step to further understand how to get more controllable, more efficient MFTS, with a higher power density and lower cost, depending on the intended application of cutting-edge DC-DC DAB-type converters.
\end{abstract}

Keywords: DC-DC converters; medium frequency transformer; nanocrystalline core; solid-state transformer

\section{Introduction}

Medium Frequency Transformers (MFTs), associated with DC-DC converters, require the highest possible power density, high efficiency, and a specific dispersion inductance at the lowest cost. Regarding this inductance, a precise knowledge of the value of this parameter is critical to set the power control range of a DC-DC DAB-type converter. To properly operate, this converter requires a minimum value of dispersion inductance at its input port. The dispersion inductance of the MFT is part of this minimum inductance. The other part is provided by an inductor external to the MFT. 
In recent years, MFTs have gained more attention [1-4], mainly because of their use in DC-DC DAB-type converters [5-8]. On the other hand, in power electronics applications, there have been advances in using a new type of semiconductor materials for the devices. These materials include Gallium Nitride (GaN), Silicon Carbide ( $\mathrm{SiC}$ ) and Gallium Oxide. These materials are expected to play an essential role in power electronics devices due to their intrinsic characteristics such as a much higher breakdown voltage and conversion efficiency [9-12]. MFTs in electronic converters are used as interfaces for the interconnection of medium-scale renewable power sources [13] to electric grids, solid-state transformers [14] and electric vehicles [15].

The MFT has been studied from various points of view: (1) noise performance, considering analysis and tests of vibrations and audible noise with toroidal cores and type CC [16]; (2) electric field study, which highlights that by using litz wire in the secondary winding, compared with foil conductor, a smaller maximum electric field intensity can be achieved [17]; (3) analysis of core manufacturing of MFTs carried out by different companies [18]. In this case, about 15 samples of each core, with similar characteristics, are taken, and the accuracy of the measurements, including losses in the core, are verified with physical prototypes; (4) loss calculation [19] by means of a new empirical calculation method based on the Steinmetz equation. Regarding design procedures, currently there are various methodologies for designing MFTs $[1-4,20]$. Each methodology proposes the use of a different geometry, opting between toroidal [1,20], shell type [2,4], or CC type [3], and different materials at specific range of frequencies; for example, silicon steel at $600 \mathrm{~Hz}$ and $1 \mathrm{kHz}[3,21]$, nanocrystalline alloys at 1 and $5 \mathrm{kHz}$ [20,22], and ferrites at $20 \mathrm{kHz}$ [2]. The purpose of each design methodology is to achieve a high efficiency, and high power density at a low construction cost. However, among the most recent publications there are few papers presenting experimental validations with physical MFTs along with comparing the characteristics and performances obtained with each core geometry.

The need to get the minimum value of the dispersion inductance with a smaller inductor external to the MFT, for attaining full control of DC-DC DAB-type converters [4], has advanced the development of MFTs with different geometries in the interest of better understanding the dispersion inductance obtained with each geometry, as well as the MFT efficiency, power density, core losses and winding losses achieved. The new knowledge thus attained can facilitate the selection of the best-performing geometry in MFT cores for a given operating condition. To date, it is not known which geometry results in better features in MFTs applied to DC-DC DAB-type converters connected to modern distribution grids.

MFTs with a toroidal core have a relatively low dispersion inductance. This implies that less dispersed flows tend to have a higher efficiency [1,20]. Research on CC-type core [3] and shell-type core $[2,4]$ report high efficiency but give little information on the dispersion inductance. Regarding toroidal cores, currently there is a wide variety of sizes on the market, in contrast to the CCand shell-type.

This research work aims to compare three core geometries (toroidal, CC- and shell-type) for designing and implementing MFTs, each one with a single type of geometry. This comparison is carried out with simulations and is verified experimentally using physical prototypes tested at the same operation conditions. All cores are of nanocrystalline alloy. As results, the advantages and disadvantages of each core geometry, highlighting the value of the dispersion inductance, are presented.

Contribution of this work: This work is a novel proposal that presents cutting-edge information about the comparison of physical prototypes of three MFT cores of different geometries (toroidal, type CC and shell-type) all operated at the same frequency and power. From the authors' perspective, the fresh information brought by the results of this comparative study, which highlights the advantages and disadvantages of each geometry, can improve the design of MFTs with respect to the increase in power density and efficiency.

This paper is organized as follows: Section 2 presents the methodology used for the design of the MFTs presented in this document. Section 3 presents the geometries used in the core of MFTs, comparing their physical dimensions and the parameters obtained from the design. Section 4 presents 
results of core losses, winding losses, design efficiencies, winding costs, core costs and total transformer cost. Section 5 presents the simulation results of MFTs submitted with sinusoidal and square signals (DAB provides these). Section 6 presents the results of an experimental test with prototypes of MFTs using sinusoidal waves. Finally, Section 7 presents a discussion of the results and Section 8 the conclusions.

\section{Design of MFTs}

The methodology used for the design of the three MFTs with a nanocrystalline core is presented in [20] and shown in Figure 1. The selection of nanocrystalline material is due to its favourable characteristics for medium frequency operation [23,24], including a high efficiency and high-power density, compared to silicon steel [3], ferrites [2] and amorphous materials [1].

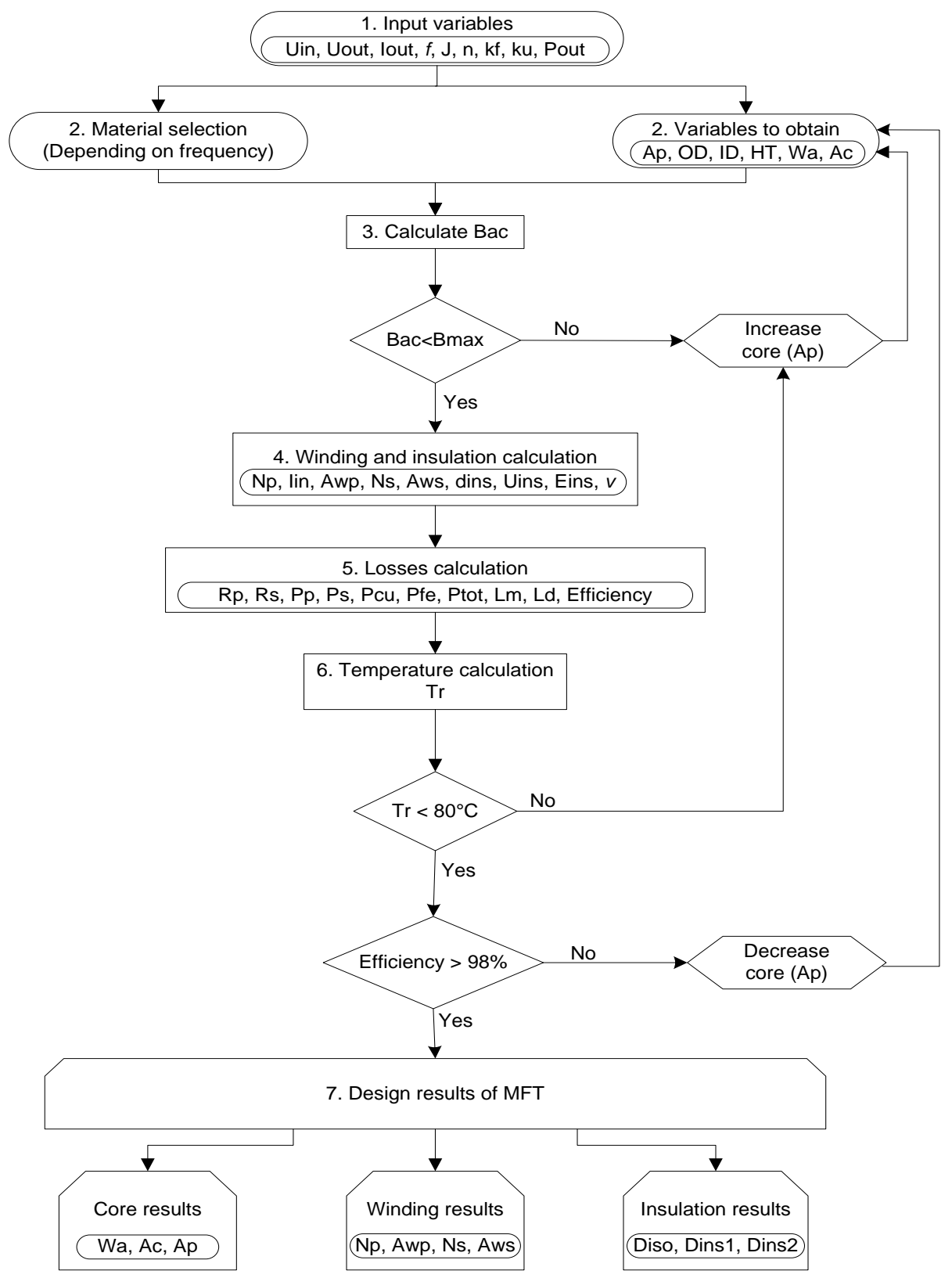

Figure 1. Medium Frequency Transformers (MFT) design procedure. 
In step 1 of the MFT design procedure, the initial values are selected: these are output power $\left(P_{\text {out }}\right)$, output current $\left(I_{\text {out }}\right)$, input voltage $\left(U_{\text {in }}\right)$, output voltage $\left(U_{\text {out }}\right)$, turns ratio $(n)$, frequency $(f)$, current density $(J)$, waveform coefficient $\left(k_{f}\right)$, and window utilization factor $\left(k_{u}\right)$. In step 2 , the core material is selected for the frequency of interest - in this case, nanocrystalline alloys. In step 3, the physical dimensions of the core are selected-in this case, for the three types of cores of interest, the window area $\left(W_{a}\right)$, the effective cross-section of the core $\left(A_{c}\right)$, and the product area $\left(A_{p}\right)$. Si $B_{a c}<B_{\max }$ (1.2 T, for nanocrystalline case), follow step 4. Otherwise, increase $A_{\mathrm{p}}\left(A_{\mathrm{p}}=W_{a} * A_{c}\right)$ and repeat from step 2 . In step 4 , the primary winding turns $\left(N_{p}\right)$, the secondary winding turns $\left(N_{s}\right)$, the input current $\left(I_{i n}\right)$, the primary wire area $\left(A_{w p}\right)$, the secondary wire area $\left(A_{w s}\right)$, the insulation dielectric rigidity $\left(E_{\text {ins }}\right)$, the minimum distance between conductors $\left(d_{\text {ins }}\right)$, the required insulation voltage $\left(U_{\text {ins }}\right)$, and the safety margin $(v)$ are all calculated. In step 5 , the magnetization inductance $\left(L_{m}\right)$, the dispersion inductance $\left(L_{d}\right)$, the primary windings resistance $\left(R_{p}\right)$, the secondary windings resistance $\left(R_{s}\right)$, the primary windings losses $\left(P_{p}\right)$, the secondary winding losses $\left(P_{s}\right)$, the copper losses $\left(P_{c u}\right)$, the core losses $\left(P_{f e}\right)$, total losses $\left(P_{t o t}\right)$ are calculated. Finally, in step 6, the temperature $\left(T_{r}\right)$ is calculated. If $T_{r}<80^{\circ} \mathrm{C}$ and the calculation of efficiency is greater than $98 \%$, then the final values of the design are obtained, such as core dimension, winding characteristics and insulation dimensions, where the insulation dimensions $D_{\text {iso }}$ are the distance between the primary and secondary winding, $D_{\text {ins } 1}$ is the minimum insulation distance between primary conductors and $D_{\text {ins } 2}$ is the minimum insulation distance between the secondary conductors.

\section{Core Geometry for MFTs}

The geometry of the core of an MFT has a significant impact on defining the value of the dispersed flow value, efficiency and power density and is essential in the value of the dispersion inductance, $L_{d}$. This value is of great interest to designers of DC-DC DAB-type converters due to its role in determining the control range of the output power of the converter. In order to achieve the control, this converter requires a minimum value of inductance to establish a phase shift, $\psi$, between $U_{\text {in }}$ and $U_{\text {out }}$, as shown in Figure 2. Commonly, the value of the dispersion inductance of an MFT is below that minimum value, therefore an inductor external to the MFT is needed. The lower $L_{d}$, the higher the external inductance.

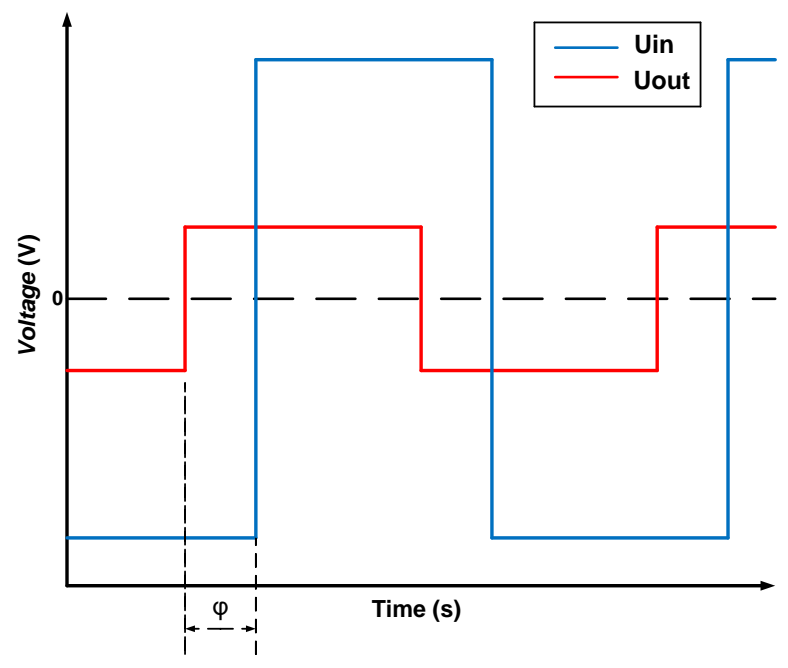

Figure 2. MFT voltages and phase shift $(\psi)$ between $U_{\text {in }}$ and $U_{\text {out }}$.

The value of the minimum dispersion inductance, $L_{\sigma}$, needed to achieve $\psi$ is given by Equation (1) [4]

$$
L_{\sigma}=\frac{U_{D C 1} U_{D C 2} \psi_{\min }\left(\pi-\psi_{\min }\right)}{2 P_{\text {out }} \pi^{2} f_{s} n}
$$


where $U_{D C 1}$ and $U_{D C 2}$ are the input voltage and output voltage of the DC-DC converter, $\psi_{\min }$ is the minimum phase shift between $U_{\text {in }}$ and $U_{\text {out }}, P_{\text {out }}$ is the output power, $f_{s}$ the operating frequency, and $n$ is the transformed ratio.

The designs published in the current literature focus only on MFTs, but not on the combined operation of an MFT and the DC-DC converter [7,20]. In some designs, the input and output voltage signals present only a minimum shift $[4,20]$, different to the shift shown in Figure 2. This represents a shorter control range of the output power of DC-DC DAB-type converters. The research on core geometries is carried out in order to identify the geometry with the best efficiency/power density/dispersion inductance relationship. With a better relationship, improved DC-DC converters, which are more efficient, with a higher power density and higher control range can be obtained.

The dimensions of the three cores, one toroidal (MFT1), one type CC (MFT2), and one shell type (MFT3), one for each MFT, are shown in Figure 3.

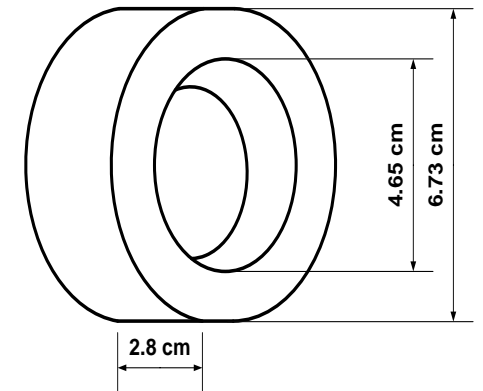

(a)
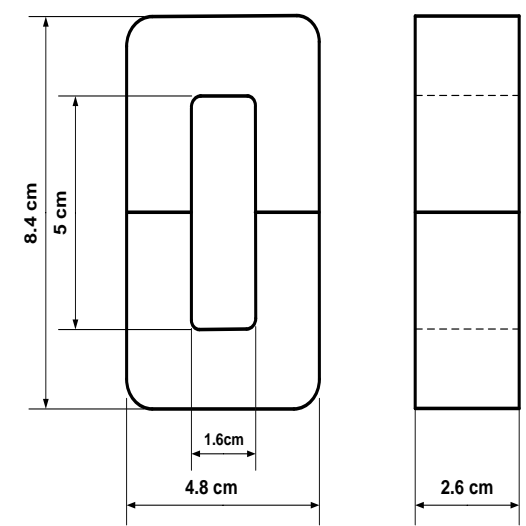

(b)
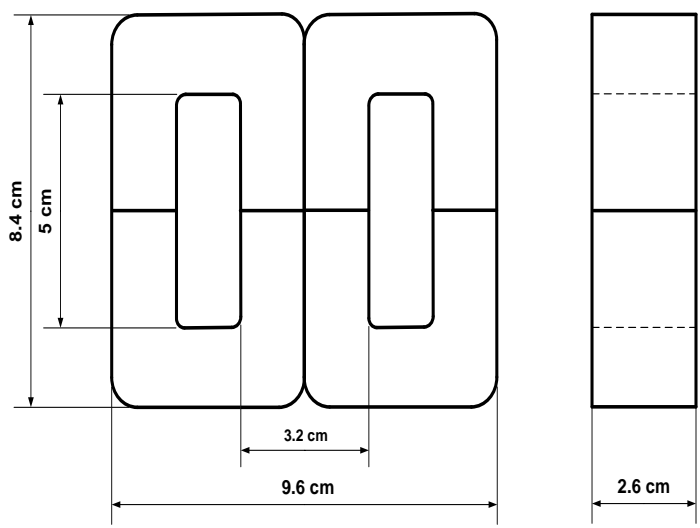

(c)

Figure 3. Core dimensions, (a) MFT1: Toroidal, (b) MFT2: CC Type, (c) MFT3: Shell Type.

Table 1 presents the volume $\left(V_{f e}\right)$ and the weight $\left(W_{f e}\right)$ of each core. Table 2 presents the design results of each MFT.

Table 1. Volume and core weight of each MFT.

\begin{tabular}{cccc}
\hline Variable & MFT1 & MFT2 & MFT3 \\
\hline$V_{f e}$ & $53.2 \mathrm{~cm}^{3}$ & $86.26 \mathrm{~cm}^{3}$ & $172.53 \mathrm{~cm}^{3}$ \\
\hline$W_{f e}$ & 161 grams & 378 grams & 756 grams \\
\hline
\end{tabular}


Table 2. Design parameters of the three MFTs.

\begin{tabular}{cccc}
\hline Variable & MFT1 & MFT2 & MFT3 \\
\hline $\mathrm{P}_{\text {out }}$ & $1750 \mathrm{VA}$ & $1750 \mathrm{VA}$ & $1750 \mathrm{VA}$ \\
$f$ & $5 \mathrm{kHz}$ & $5 \mathrm{kHz}$ & $5 \mathrm{kHz}$ \\
$\mathrm{U}_{\text {in }}$ & $280 \mathrm{~V}$ & $280 \mathrm{~V}$ & $280 \mathrm{~V}$ \\
$\mathrm{U}_{\text {out }}$ & $670 \mathrm{~V}$ & $670 \mathrm{~V}$ & $670 \mathrm{~V}$ \\
$\mathrm{I}_{\text {out }}$ & $2.61 \mathrm{~A}$ & $2.61 \mathrm{~A}$ & $2.61 \mathrm{~A}$ \\
Number of phases & 1 - phase & 1 - phase & 1 - phase \\
Core material & Nanocrystalline & Nanocrystalline & Nanocrystalline \\
Core type & (Vitroperm500F) & (Vitroperm500F) & (Vitroperm500F) \\
$\mathrm{N}_{\mathrm{p}}$ & Toroidal & Type CC & Shell-type \\
$\mathrm{N}_{\mathrm{s}}$ & 96 & 42 & 23 \\
Primary winding calibre & 233 & 101 & 56 \\
Secondary winding & $14 \mathrm{AWG}$ & $14 \mathrm{AWG}$ & $14 \mathrm{AWG}$ \\
calibre & $18 \mathrm{AWG}$ & $18 \mathrm{AWG}$ & $18 \mathrm{AWG}$ \\
$\mathrm{L}_{\mathrm{d}}$ & $37.9 \mu \mathrm{H}$ & $195.1 \mu \mathrm{H}$ & $6.1 \mu \mathrm{H}$ \\
$\mathrm{B}_{\mathrm{ac}}$ & $0.9 \mathrm{~T}$ & $0.9 \mathrm{~T}$ & $0.9 \mathrm{~T}$ \\
\hline
\end{tabular}

According to Table 1, the MFT1 has the smallest volume, and the MFT3 has the largest. Also, Table 2 shows that the MFT3 has a lower number of turns and the MFT1 has the highest.

\section{Losses in Winding and Core}

In MFT designs, it is always of interest to achieve high efficiency while keeping losses low. Core losses are associated with the type of core material, the material permeability, and the flow density, all defined in the MFT design. The losses in the medium frequency range have been reduced using nanocrystals and amorphous materials $[4,20,23]$. In this work, the three cores are nanocrystalline.

This section presents the losses of the winding and the core calculated for each of the three MFTs using the method described in [20]. Figure 4 shows the losses in the winding and Figure 5 the losses in the core of the three MFTs.

According to Figure 4, MFT1 had the most significant losses in the winding, with $15.8 \%$ and $53 \%$ higher than MFT2 and MFT3, respectively. Figure 5 shows the losses in the core. These are $27 \%$ and 96.3\% higher in MFT2 and MFT3 than in MFT1, respectively.

The MFT1 has lower total losses due to the type of the core geometry and its lower dispersed flow. The latter means a greater confinement of the magnetic flux in the core. MFTs with CC-type core and shell-type have higher losses than MFT1. This is partly explained by the gap and increased dispersed flow due to the two-part structure of the cores, which results in higher losses [16].

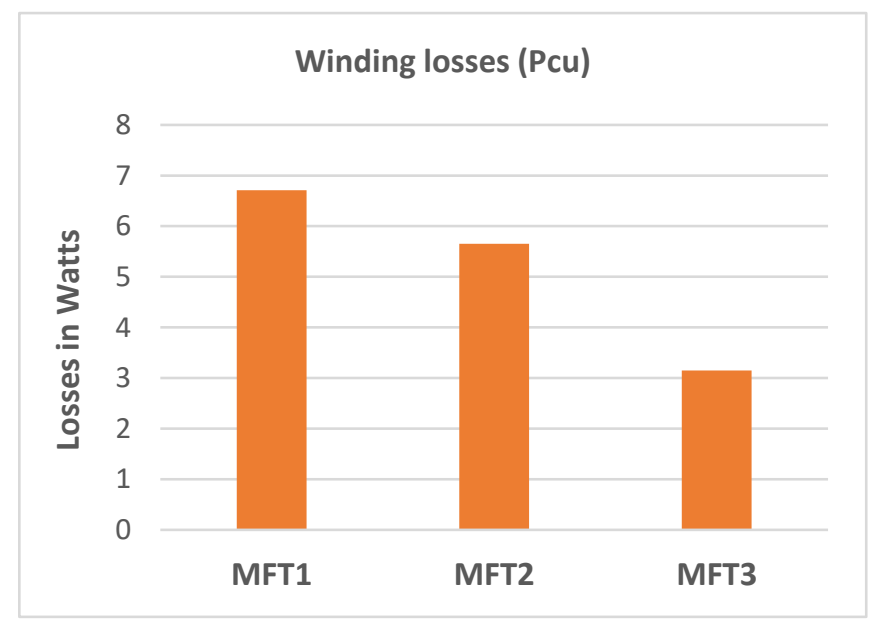

Figure 4. Losses of windings of the three MFTs. 


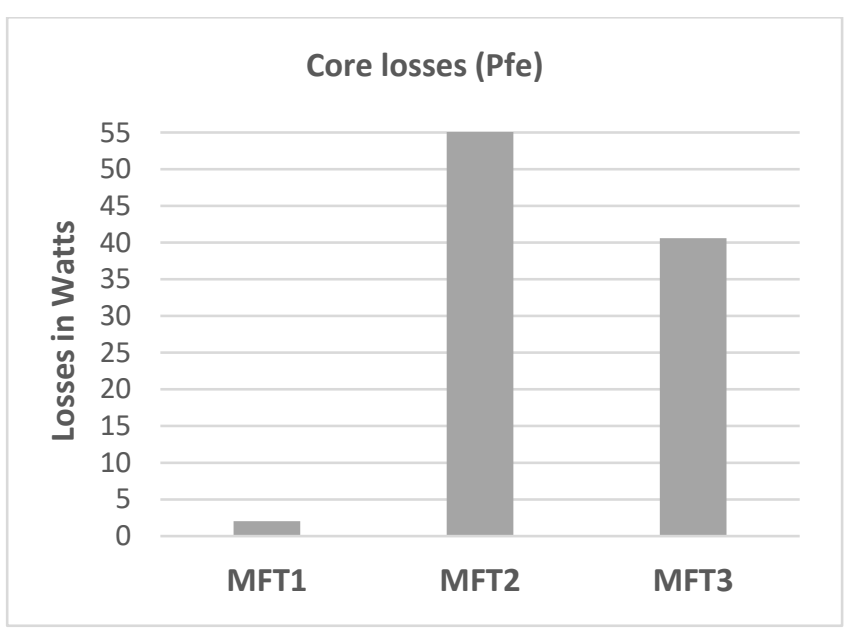

Figure 5. Losses in the core of the three MFTs.

Table 3 shows the values of core losses and losses in the winding of the three MFTs. Table 4 shows the efficiency of these MFTs.

Table 3. Losses in winding $\left(P_{c u}\right)$, core losses $\left(P_{f e}\right)$ and total losses $\left(P_{t o t}\right)$ of the MFTs.

\begin{tabular}{cccc}
\hline Variable & MFT1 & MFT2 & MFT3 \\
\hline$P_{c u}$ & $6.71 \mathrm{~W}$ & $5.65 \mathrm{~W}$ & $3.15 \mathrm{~W}$ \\
$P_{f e}$ & $2.04 \mathrm{~W}$ & $55.6 \mathrm{~W}$ & $40.60 \mathrm{~W}$ \\
$P_{\text {tot }}$ & $8.75 \mathrm{~W}$ & $61.25 \mathrm{~W}$ & $43.75 \mathrm{~W}$ \\
\hline
\end{tabular}

Table 4. MFTs efficiencies.

\begin{tabular}{llll}
\hline & MFT1 & MFT2 & MFT3 \\
\hline Efficiency & $99.5 \%$ & $96.5 \%$ & $97.5 \%$ \\
\hline
\end{tabular}

The validation of the results of Tables 3 and 4 are presented in Section 6, using the results obtained from three experimental prototypes. The essential cost of the three MFTs is presented in Table 5.

Table 5. Winding cost $\left(C_{c u}\right)$, core cost $\left(C_{f e}\right)$ and total cost $\left(C_{t o t}\right)$ of MFTs.

\begin{tabular}{cccc}
\hline Variable & MFT1 & MFT2 & MFT3 \\
\hline$C_{c u}$ & 5.13 USD & 2.36 USD & 1.02 USD \\
$C_{f e}$ & 84.14 USD & 247.95 USD & 495.9 USD \\
$C_{t o t}$ & 89.27 USD & 250.31 USD & 496.92 USD \\
\hline
\end{tabular}

According to Table 5, the core of the MFT1 has the lowest total cost even when its winding cost is higher, due to the low cost of its core. The core cost of the MFT2 is lower than that of the MFT3, but the winding cost is higher because the MFT3 is built with two CC cores and the MFT2 is built with only one CC core. The MFT3 is a higher cost transformer, mainly due to the core of the MFT.

\section{Simulations}

The behaviours of the three MFTs are simulated at the same input power, frequency (using sinusoidal signal) and load conditions. In addition, with the purpose of analysing the behaviour of the MFT under square signals, the transformer is connected to a DAB. Figure 6 shows the MFT testing system for sinusoidal waveforms, and Figure 7 shows the testing system for square waveforms. 


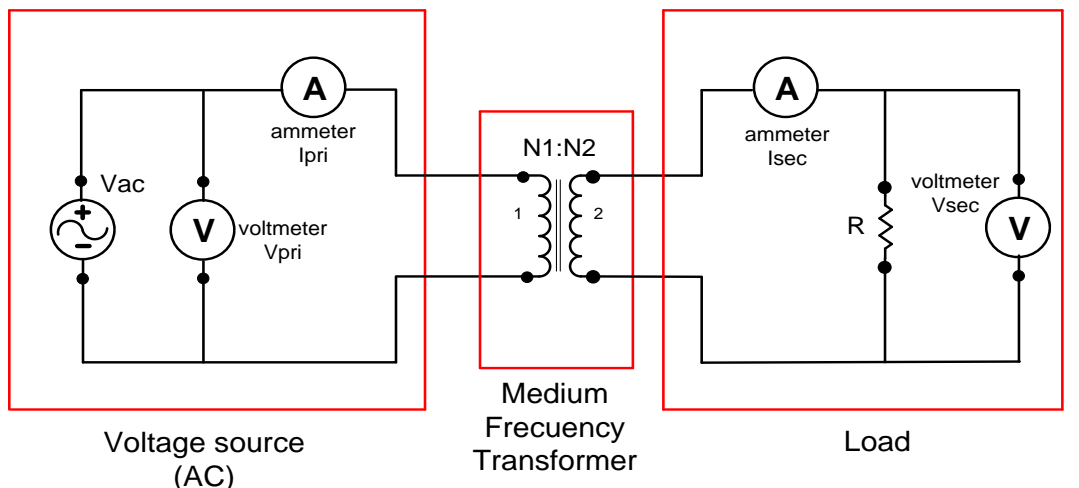

Figure 6. MFT testing system for sinusoidal waveforms.

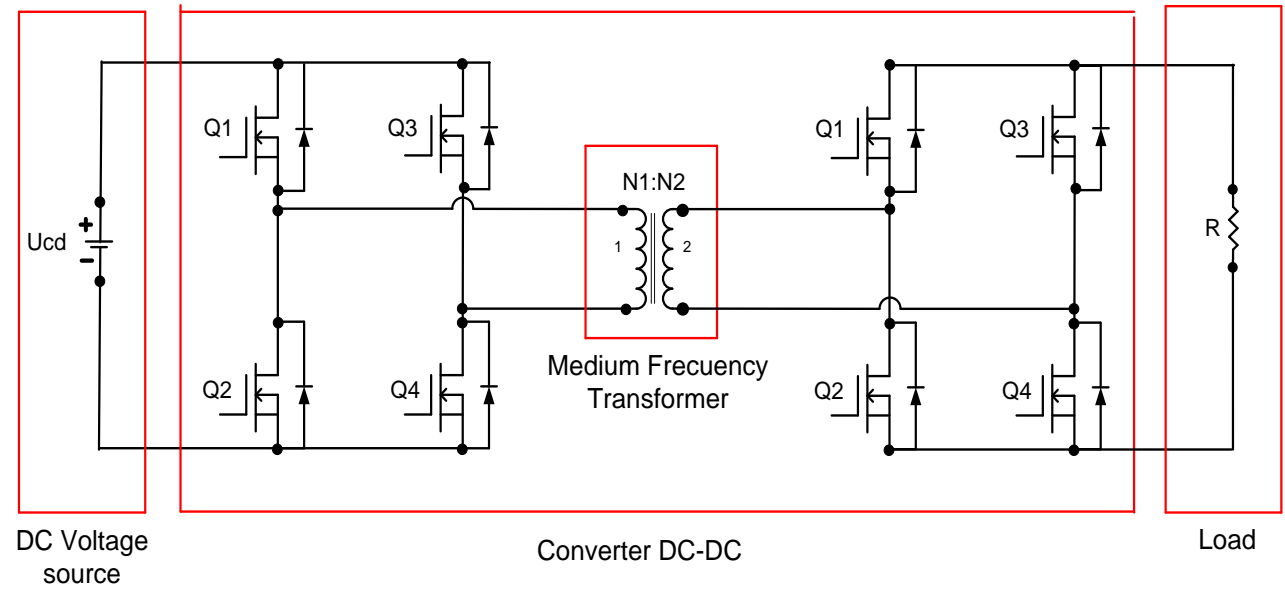

Figure 7. MFT testing system for square waveforms.

Table 6 shows the parameters of the three MFTs used in simulations. Notice that MFT2 has the highest dispersion inductance, $L_{d 1}$. Therefore, it has the highest output power control range. It should be mentioned that a lower $L_{d 1}$ lowers $\psi$.

Table 6. Parameters of the model of the MFTs for simulation.

\begin{tabular}{cccc}
\hline Variable & MFT1 & MFT2 & MFT3 \\
\hline$P_{\text {out }}$ & $1750 \mathrm{VA}$ & $1750 \mathrm{VA}$ & $1750 \mathrm{VA}$ \\
$f$ & $5 \mathrm{kHz}$ & $5 \mathrm{kHz}$ & $5 \mathrm{kHz}$ \\
$U_{\text {in }}$ & $280 \mathrm{~V}$ & $280 \mathrm{~V}$ & $280 \mathrm{~V}$ \\
$U_{\text {out }}$ & $670 \mathrm{~V}$ & $670 \mathrm{~V}$ & $670 \mathrm{~V}$ \\
$R_{1}$ & $91.1 \mathrm{~m} \Omega$ & $62 \mathrm{~m} \Omega$ & $38.5 \mathrm{~m} \Omega$ \\
$R_{2}$ & $681.2 \mathrm{~m} \Omega$ & $428 \mathrm{~m} \Omega$ & $236.2 \mathrm{~m} \Omega$ \\
$L_{\mathrm{d} 1}$ & $37.9 \mu \mathrm{H}$ & $195.1 \mu \mathrm{H}$ & $6.1 \mu \mathrm{H}$ \\
$L_{\mathrm{d} 2}$ & $206.4 \mu \mathrm{H}$ & $1.14 \mathrm{mH}$ & $96 \mu \mathrm{H}$ \\
$R_{\mathrm{m}}$ & $5731.55 \Omega$ & $13,499.29 \Omega$ & $5264.3 \Omega$ \\
$L_{\mathrm{m}}$ & $1.60 \mathrm{H}$ & $131.16 \mathrm{mH}$ & $100.48 \mathrm{mH}$ \\
\hline
\end{tabular}

Figures 8 and 9 show the input and output voltages and currents of the three MFTs fed with sinusoidal and square signals, respectively. Tables 7 and 8 present the voltage and current values, as well as the efficiency of each MFT fed with sinusoidal and square signals, respectively. 

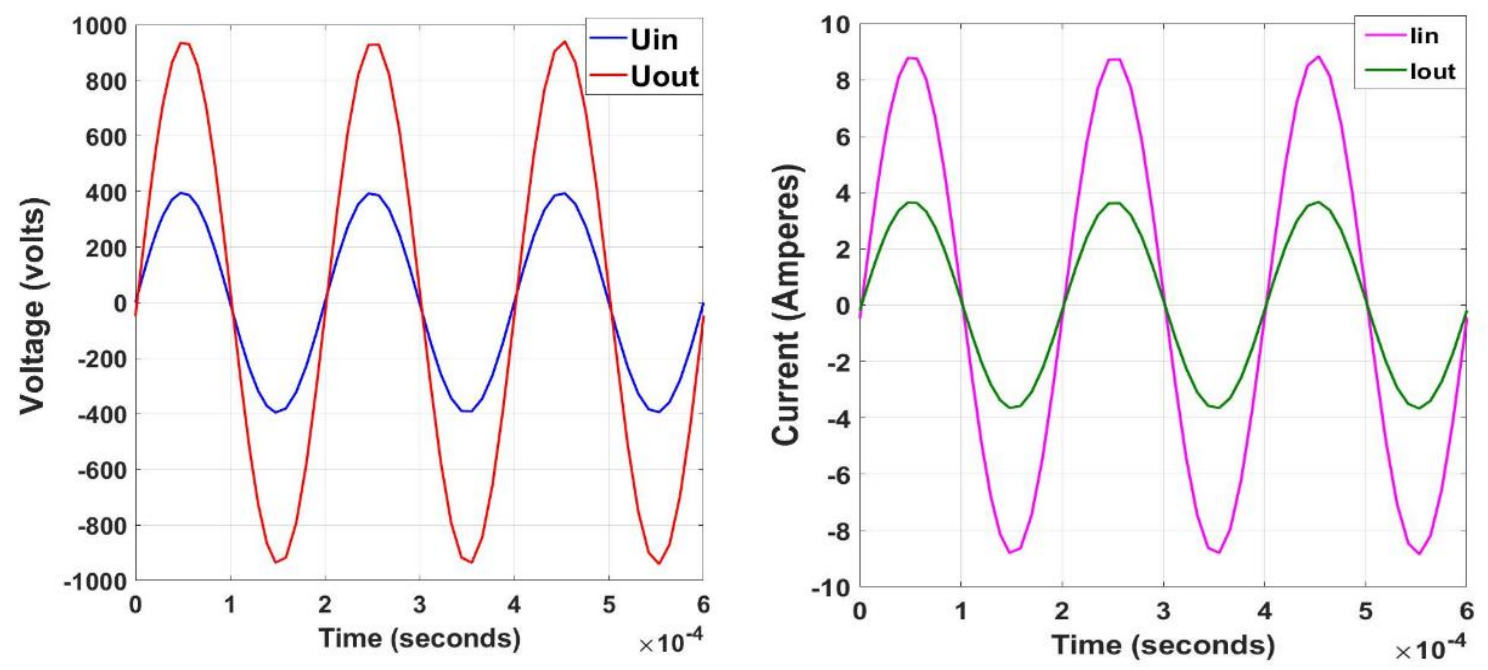

(a)
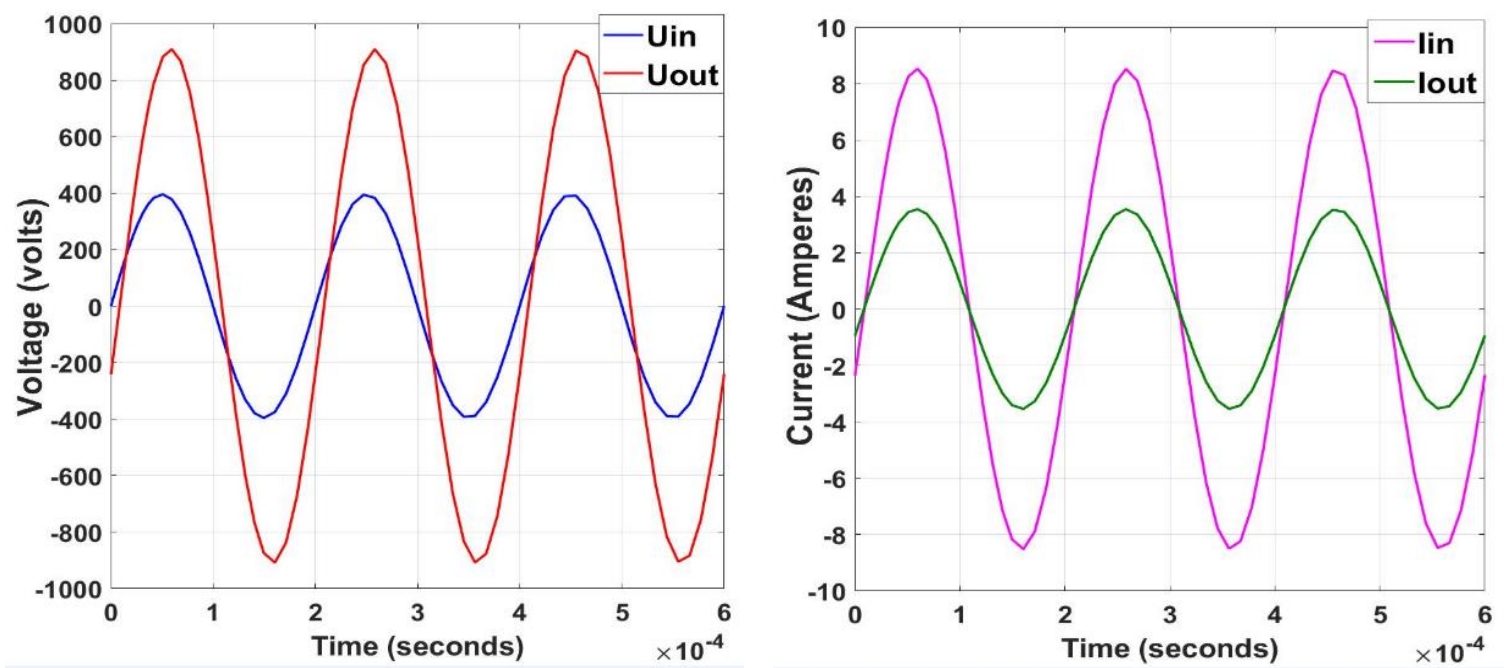

(b)
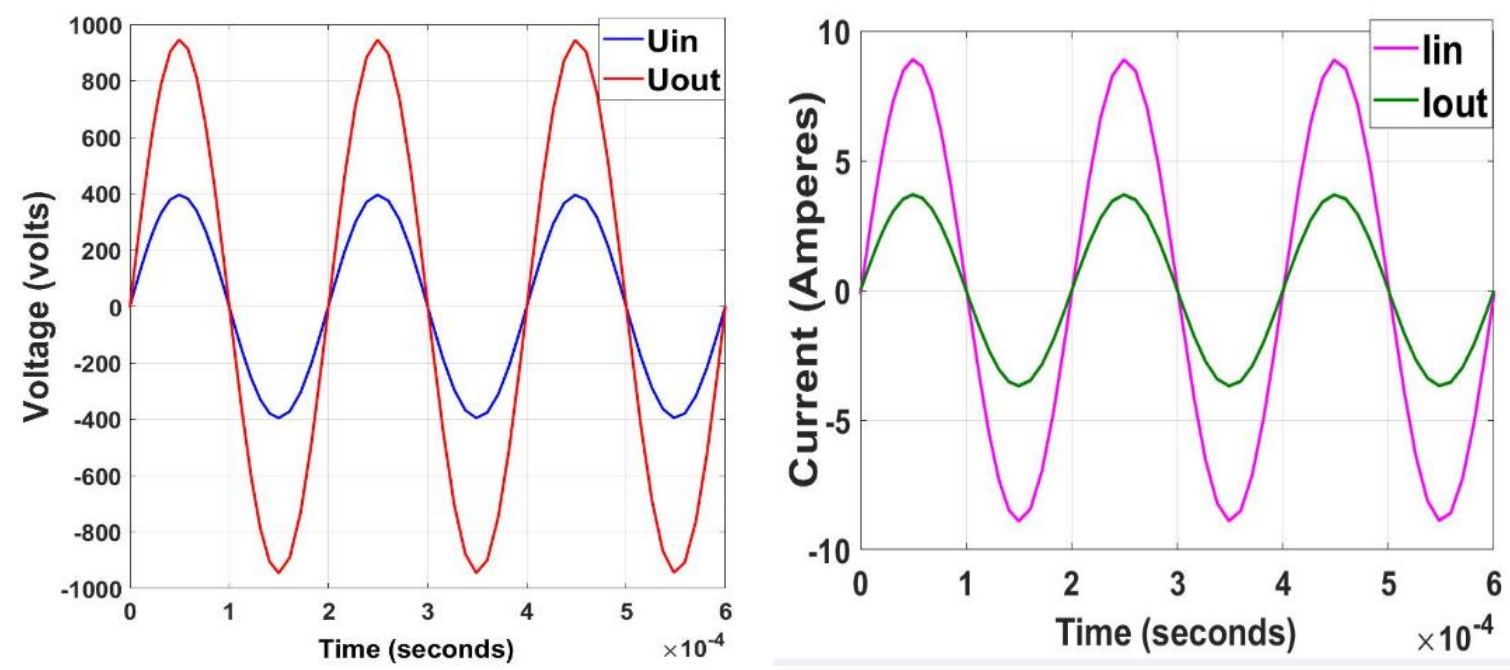

(c)

Figure 8. Input and output voltages and currents of MFTs in sine wave simulation, (a) MFT1, (b) MFT2, (c) MFT3. 

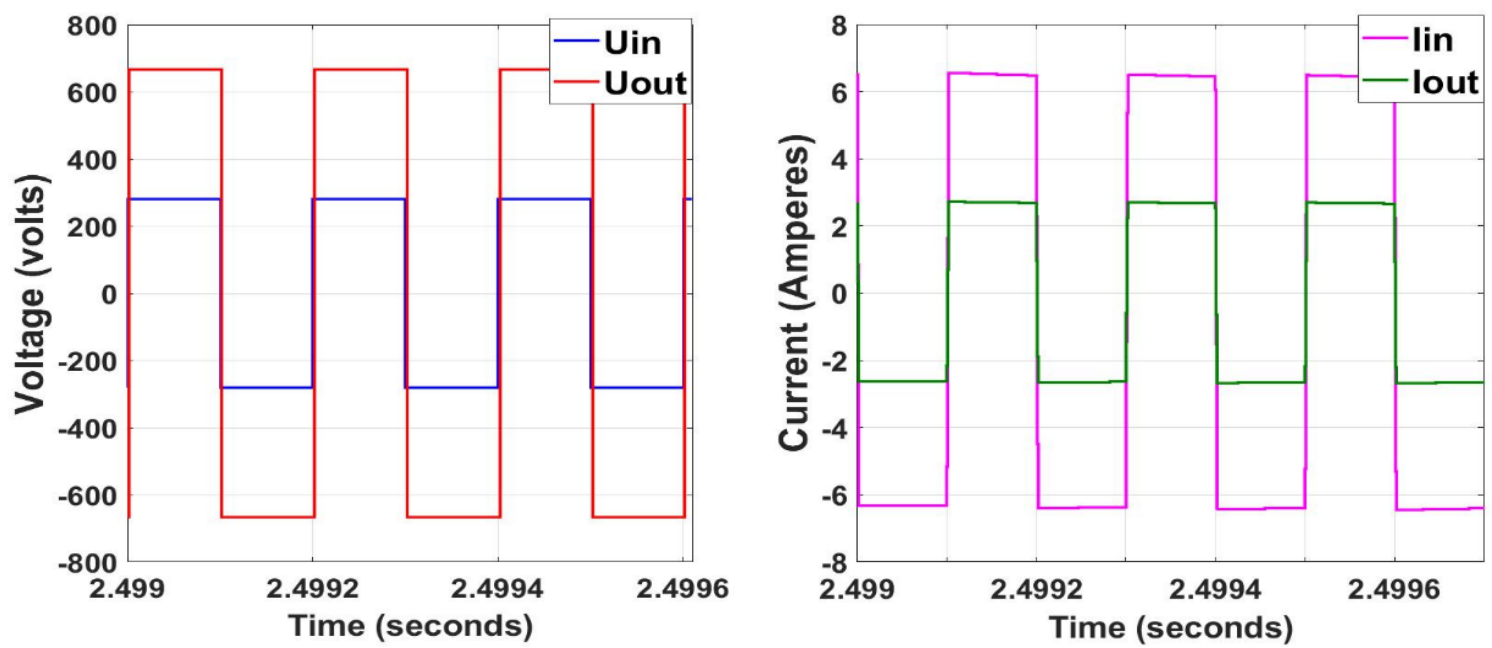

(a)
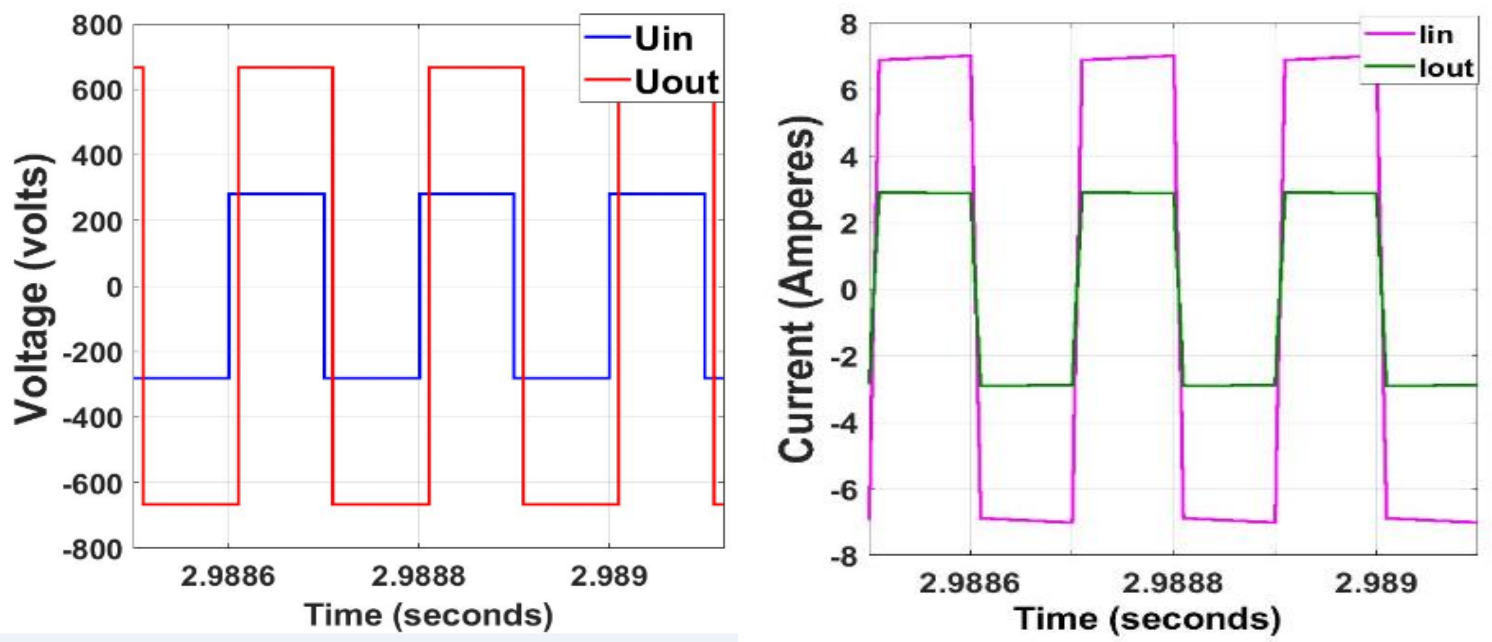

(b)
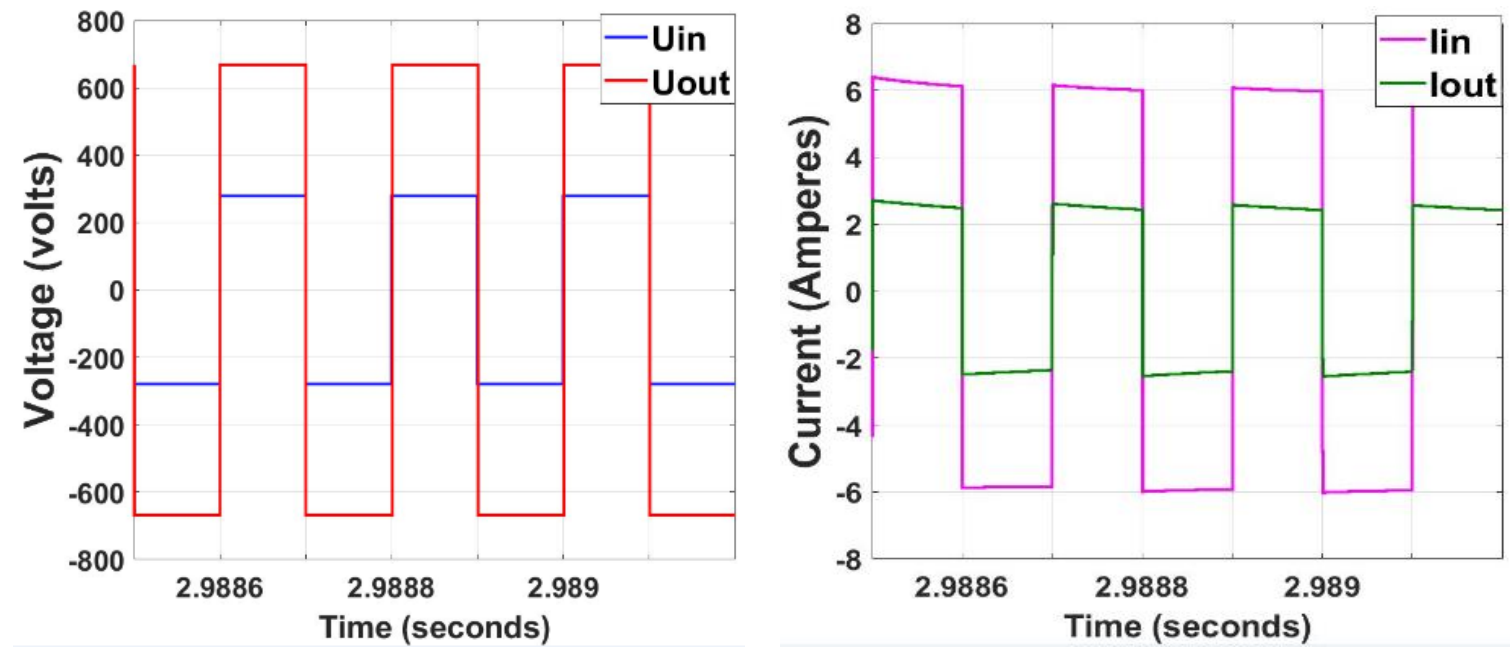

(c)

Figure 9. Input and output voltages and currents of MFTs in square wave simulation, (a) MFT1, (b) MFT2, (c) MFT3. 
Table 7. Simulation results with sine waves.

\begin{tabular}{cccc}
\hline Variable & MFT1 & MFT2 & MFT3 \\
\hline$U_{\text {in }}$ & $280 \mathrm{~V}$ & $280 \mathrm{~V}$ & $280 \mathrm{~V}$ \\
$U_{\text {out }}$ & $665.84 \mathrm{~V}$ & $642.99 \mathrm{~V}$ & $668.79 \mathrm{~V}$ \\
$I_{\text {in }}$ & $6.26 \mathrm{~A}$ & $6.03 \mathrm{~A}$ & $6.29 \mathrm{~A}$ \\
$I_{\text {out }}$ & $2.6 \mathrm{~A}$ & $2.53 \mathrm{~A}$ & $2.58 \mathrm{~A}$ \\
Efficiency & $98.76 \%$ & $96.35 \%$ & $97.97 \%$ \\
\hline
\end{tabular}

Table 8. Simulation results with square waves.

\begin{tabular}{cccc}
\hline Variable & MFT1 & MFT2 & MFT3 \\
\hline$U_{\text {in }}$ & $279.7 \mathrm{~V}$ & $279.6 \mathrm{~V}$ & $279.6 \mathrm{~V}$ \\
$U_{\text {out }}$ & $668 \mathrm{~V}$ & $666.6 \mathrm{~V}$ & $668.4 \mathrm{~V}$ \\
$I_{\text {in }}$ & $6.416 \mathrm{~A}$ & $7.016 \mathrm{~A}$ & $6.02 \mathrm{~A}$ \\
$I_{\text {out }}$ & $2.658 \mathrm{~A}$ & $2.883 \mathrm{~A}$ & $2.47 \mathrm{~A}$ \\
Efficiency & $98.94 \%$ & $97.96 \%$ & $98.08 \%$ \\
\hline
\end{tabular}

As shown in Table 7, MFT1 has $2.41 \%$ and $0.79 \%$ higher efficiency than MFT2 and MFT3, respectively.

According to Table 8 , the MFT1 has $0.18 \%$ higher efficiency with square waveforms than with sinusoidal, while the MFT2 is more efficient at $1.61 \%$ and the MFT3 is $0.11 \%$. In Section 5 , these results are validated using MFT prototypes. On the other hand, these results corroborate what is presented in [25], where it was found that MFTs tend towards lower losses in the core with square waves than with sine waves. For this reason, and because of the availability of laboratory equipment, Section 5 corroborates these results using MFT prototypes with a sine wave and knowing that, with square waves, greater efficiencies would be obtained [25].

\section{Experimental Prototype}

The laboratory prototypes of the three MFTs are presented in Figure 10. Each prototype is tested in the laboratory with sinusoidal signals with an AC POWER SOURCE/ANALYSER AGILENT 6834b, at identical load conditions, $256.5 \Omega$, and frequency of $5 \mathrm{kHz}$.

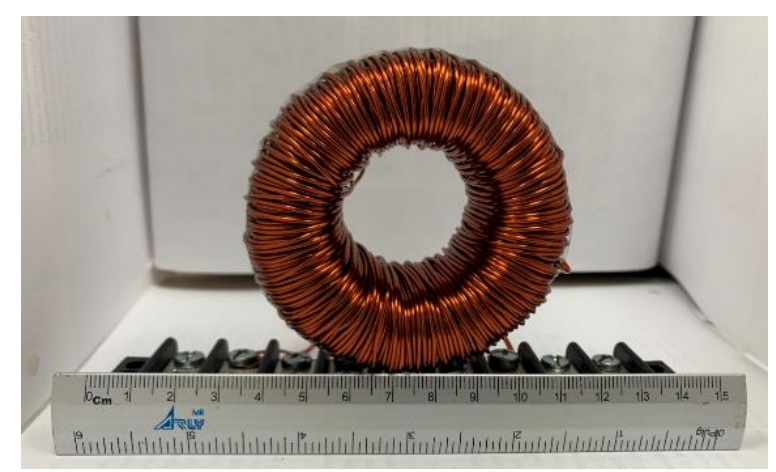

(a)

Figure 10. Cont. 


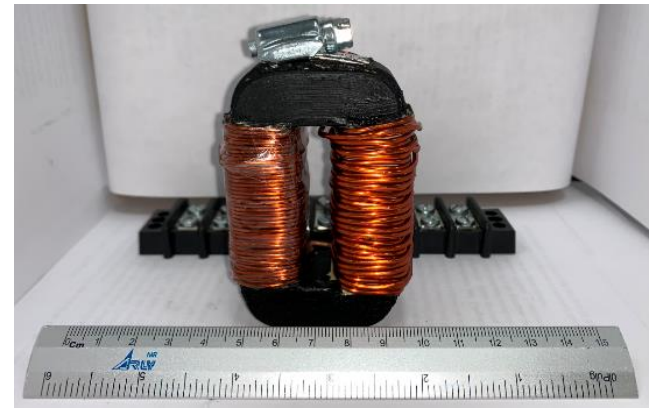

(b)

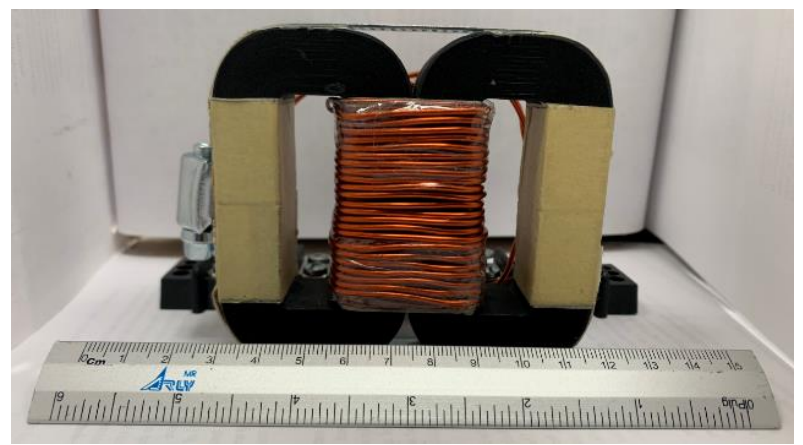

(c)

Figure 10. MFTs prototype, (a) MFT1, (b) MFT2, (c) MFT3.

Figure 11 presents the experimental laboratory platform used to obtain the experimental results with three prototypes of MFTs.

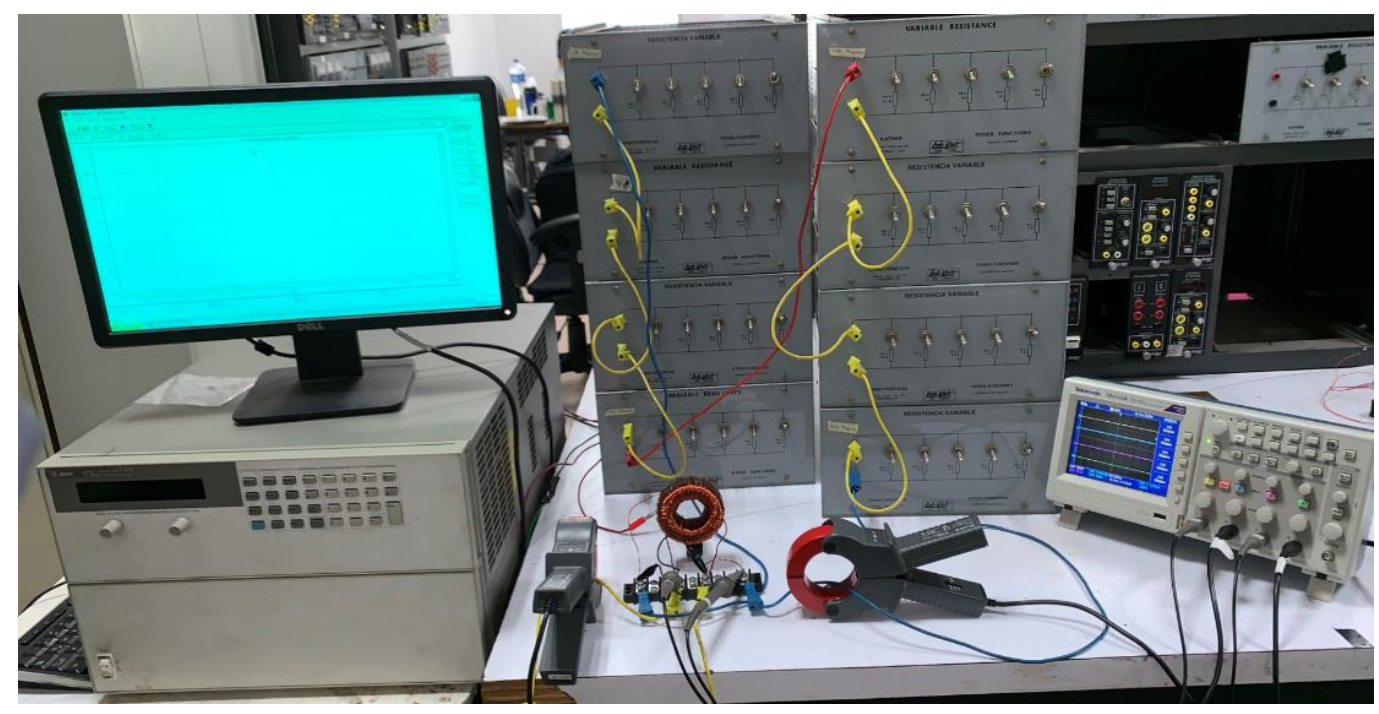

Figure 11. Experimental platform for MFT prototype with voltage source at $280 \mathrm{~V}$ input, $5 \mathrm{kHz}$ and a load of $256.5 \Omega$, with the MFT1 as an example.

Figure 12 presents the block diagram of the experimental setup of Figure 11. 


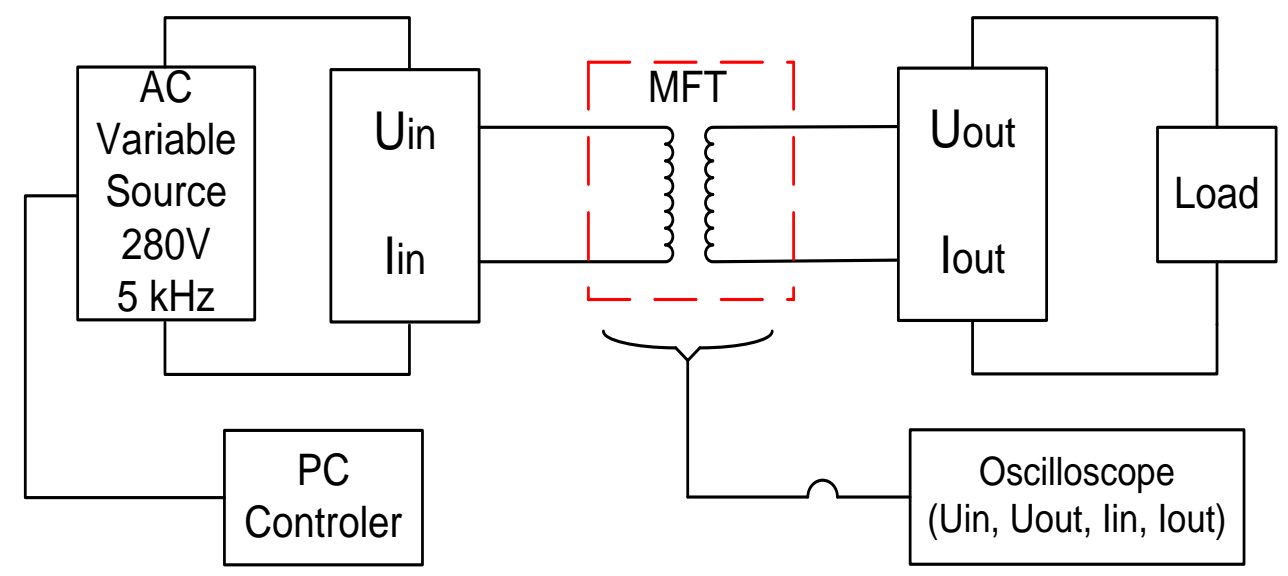

Figure 12. Block diagram of the experimental setup.

Figures 13-15 show the input and output voltages and currents of the experimental prototypes MFT1, MFT2, and MFT3, respectively.

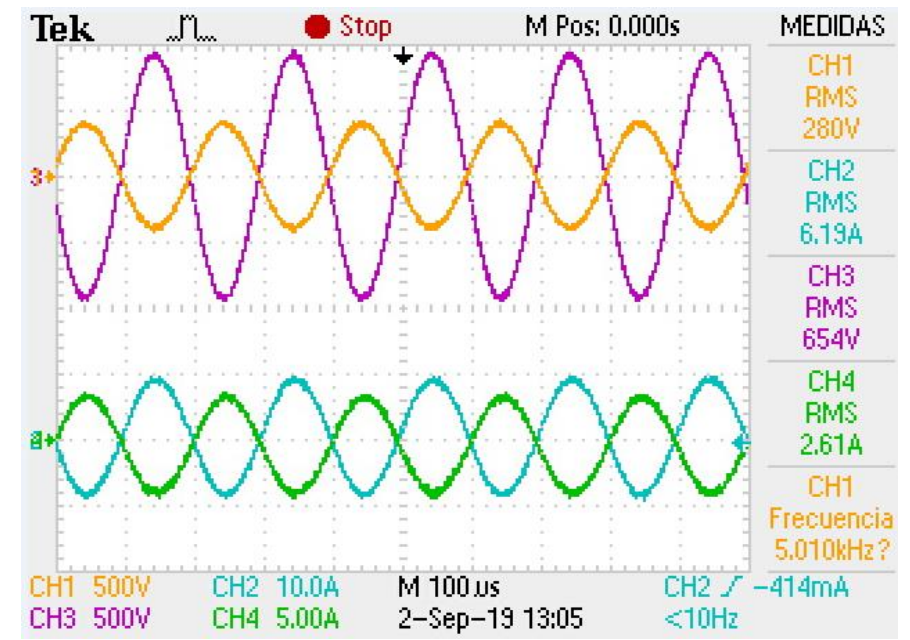

Figure 13. $U_{\text {in }}(\mathrm{CH} 1), I_{\text {in }}(\mathrm{CH} 2), U_{\text {out }}(\mathrm{CH} 3)$, and $I_{\text {out }}(\mathrm{CH} 4)$ of the MFT1 lab prototype.

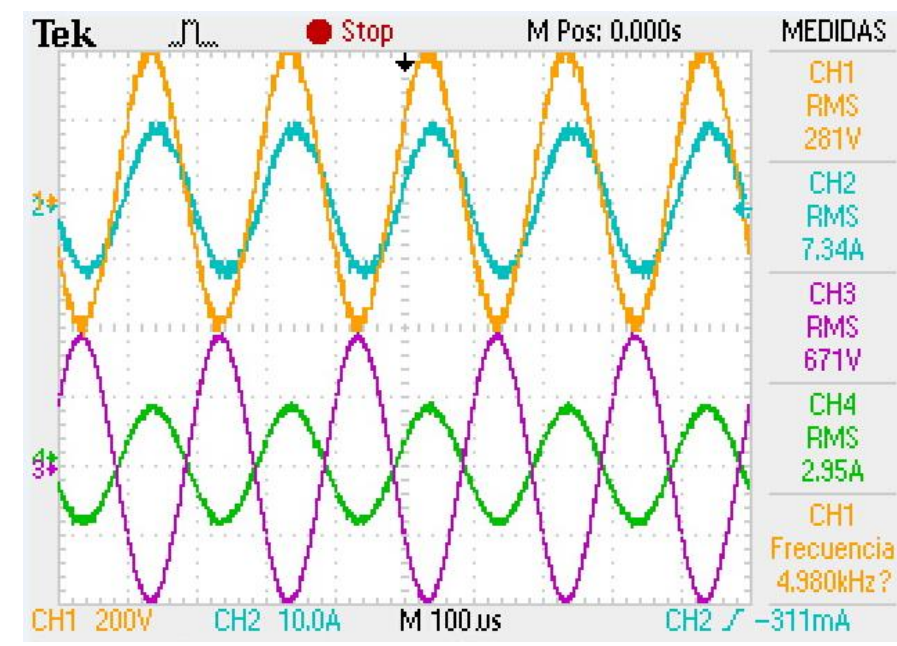

Figure 14. $U_{\text {in }}(\mathrm{CH} 1), I_{\text {in }}(\mathrm{CH} 2), U_{\text {out }}(\mathrm{CH} 3)$, and $I_{\text {out }}(\mathrm{CH} 4)$ of the MFT2 lab prototype. 


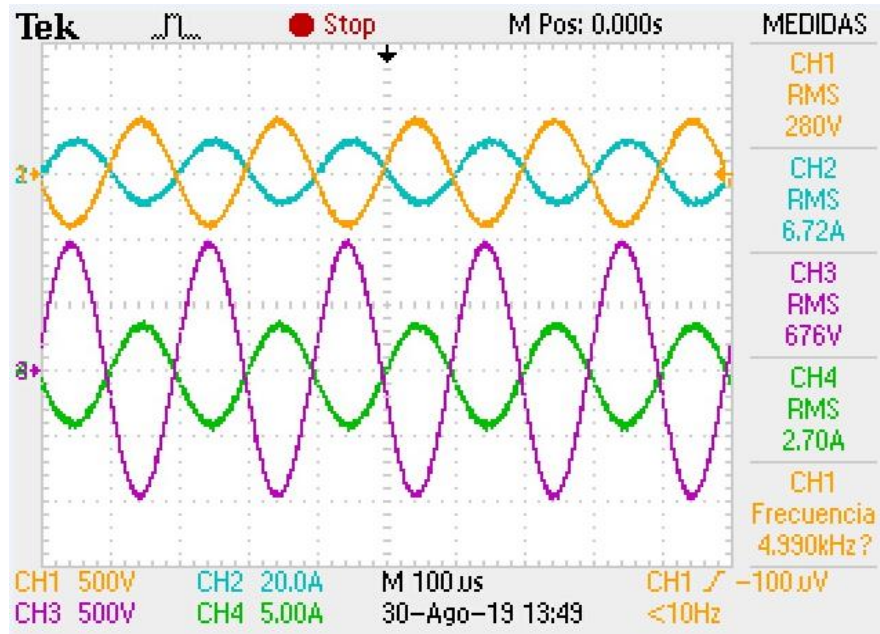

Figure 15. $U_{\text {in }}(\mathrm{CH} 1), I_{\text {in }}(\mathrm{CH} 2), U_{\text {out }}(\mathrm{CH} 3)$, and $I_{\text {out }}(\mathrm{CH} 4)$ of the MFT3 lab prototype.

The input and output voltage and current values, as well as the efficiency of the three MFTs, are presented in Table 9.

Table 9. Experimental results.

\begin{tabular}{cccc}
\hline Variable & MFT1 & MFT2 & MFT3 \\
\hline$U_{\text {in }}$ & $280 \mathrm{~V}$ & $281 \mathrm{~V}$ & $280 \mathrm{~V}$ \\
$U_{\text {out }}$ & $654 \mathrm{~V}$ & $671 \mathrm{~V}$ & $676 \mathrm{~V}$ \\
$I_{\text {in }}$ & $6.19 \mathrm{~A}$ & $7.34 \mathrm{~A}$ & $6.72 \mathrm{~A}$ \\
$I_{\text {out }}$ & $2.61 \mathrm{~A}$ & $2.95 \mathrm{~A}$ & $2.70 \mathrm{~A}$ \\
Efficiency & $98.5 \%$ & $96 \%$ & $97 \%$ \\
\hline
\end{tabular}

According to Table 9, the MFT1 has the highest efficiency, resulting in the most attractive core option for use in MFTs. In contrast, due to the structure of cut cores or two-part cores, the MFT2 and MFT3 have a lower efficiency. The cut cores have the convenience of a relatively straightforward implementation but have very thin air gaps, which contribute to increasing the dispersed flow of the transformer and, therefore, to the increase in total loss [16].

\section{Discussion}

Table 10 presents the most recent research on MFTs with toroidal core, CC core and shell core operating at a medium frequency range.

Table 10. Recent MFTs designed with different geometries.

\begin{tabular}{cccccc}
\hline Core & Material & Power & Frequency & Power density & Efficiency \\
\hline Toroidal [20] & Nanocrystalline & $1 \mathrm{kVA}$ & $5 \mathrm{kHz}$ & $15.01 \mathrm{~kW} / 1$ & $99.41 \%$ \\
Toroidal [22] & Nanocrystalline & $1 \mathrm{kVA}$ & $1 \mathrm{kHz}$ & $2.51 \mathrm{~kW} / 1$ & $99.11 \%$ \\
Type CC [21] & Silicon steel & $0.8 \mathrm{kVA}$ & $0.6 \mathrm{kHz}$ & $1.29 \mathrm{~kW} / 1$ & $99.00 \%$ \\
Type CC [3] & Silicon steel & $35 \mathrm{kVA}$ & $1 \mathrm{kHz}$ & $2.96 \mathrm{~kW} / 1$ & $99.40 \%$ \\
Shell-type [4] & Ferrite/Nanocryst. & $50 \mathrm{kVA}$ & $5 \mathrm{kHz}$ & $11.5 \mathrm{~kW} / 1$ & $99.48 \%$ \\
Shell-type [2] & Ferrite & $10 \mathrm{kVA}$ & $20 \mathrm{kHz}$ & $9.25 \mathrm{~kW} / 1$ & $99.22 \%$ \\
\hline
\end{tabular}

Each proposal in Table 10 includes an experimental prototype. In [20] and [22], an MFT with the toroidal core is presented, tested at 5 and $1 \mathrm{kHz}$, respectively. Both MFTs have an efficiency above $99 \%$, at $1 \mathrm{kVA}$ but the difference between them is the power density, which was $83.3 \%$ higher in the MFT at $5 \mathrm{kHz}$. This difference is because the higher the frequency, the higher the power density. 
In [21] and [3], CC cores are used. Although this type of core has a very thin air gap, there is an increase in dispersed flow and, finally, an increase in losses, thus reducing efficiency. The difference between this core and the toroidal is presented in Section 6 .

Using other type of core, in [4] and [2] shell cores are used, at 5 and $20 \mathrm{kHz}$ with powers at 50 and $10 \mathrm{kVA}$, respectively. The MFT in this case has an efficiency of $97 \%$ at $1.75 \mathrm{kVA}$ and $5 \mathrm{kHz}$. On the other hand, the dispersion inductance is lower than in other MFTs. This is due to the core structure, which concentrates most of the magnetic flux in the transformer core.

The magnitude of the dispersion inductance is key to defining the power output control of DC-DC converters with $\mathrm{DAB}$. This is because these converters require a minimum dispersion inductance to establish the amplitude of the control range of the output power [4].

The analysis and results presented in this research work provide useful information for the selection of the most suitable core geometry to meet the requirements of high efficiency or a higher output power control range, for example. A design objective is to obtain a high value for the dispersion inductance in the MFT in order to use inductances external to the MFT. If the MFT alone has, or surpasses, the minimum dispersion inductance, then the external inductances might not be necessary. In this case, a wide-range output power control of the DC-DC converter can be achieved.

\section{Conclusions}

The analysis, development and evaluation of the MFTs are fundamental for the advancement of DC-DC converters towards more efficient, lower cost and higher power density structures, applicable to wind systems, photovoltaic systems, electric vehicles and solid-state transformers. The core geometry, the core material, and the availability of design procedures are key to the development of new MFTs. In this article, a comparison is made between three nanocrystalline core geometries, a toroidal core, a CC-type core and a shell-type core, were applied to MFTs designed with the same characteristics$1.75 \mathrm{kVA}$ at $5 \mathrm{kHz}$. All MFTs were designed using the method presented in [20]. The three MFTs were analysed with their physical dimensions and evaluated both in simulation and experimentally with a prototype in the laboratory. The MFT with a toroidal core exhibited lower core losses, lower total losses, a higher efficiency, lower core volume, lower core cost, and a lower total MFT cost. The MFT with a CC-type core exhibited a lower total volume, higher power density, and a higher dispersion inductance value. Finally, the MFT with a shell-type core had the lowest volume in the winding of the transformer and lower losses in the winding. Considering that efficiency and power density are some of the main objectives in the design of MFTs, the MFT with a toroidal core has excellent potential. Another relevant parameter for the CD-CD converter is dispersion inductance. The MFT with a CC core had the highest dispersion inductance. This results in a higher output power control range.

Author Contributions: Performed prototype experiments, D.R.-R., and C.F.-B.; conceptualization, D.R.-R., and E.L.M.-G.; methodology, D.R.-R.; validation, D.R.-R., C.F.-B., and V.V.-R.; formal analysis, V.V.-R., and E.L.M.-G.; investigation, D.R.-R., and C.F.-B.; resources, V.V.-R., and E.L.M.-G.; writing-original draft preparation, D.R.-R; writing-review and editing, E.L.M.-G; supervision, V.V.-R., and E.L.M.-G.; all the authors contributed to the review of the paper. All authors have read and agreed to the published version of the manuscript.

Funding: This research received no external funding.

Acknowledgments: The authors thank the TNM (Tecnológico Nacional de México/Instituto Tecnológico de Morelia) and CONACYT for supporting our research and projects leading to the writing of present paper.

Conflicts of Interest: The authors declare no conflict of interest.

\section{References}

1. Jafari, M.; Malekjamshidi, Z.; Lei, G.; Wang, T.; Platt, G.; Zhu, J. Design and implementation of an amorphous high-frequency transformer coupling multiple converters in a smart microgrid. IEEE Trans. Ind. Electron. 2017, 64, 1028-1037. [CrossRef] 
2. Bediaga, A.G.; Villar, I.; Rujas, A.; Mir, L.; Rufer, A. Multiobjetive optimization of medium-frequency transformer for isolated soft-switching converters using a genetic algorithm. IEEE Trans. Power Electron. 2017, 32, 2995-3006. [CrossRef]

3. Huang, P.; Mao, C.; Wang, D.; Wang, L.; Duan, Y.; Qiu, J.; Xu, G.; Cai, H. Optimal design and implementation of high-voltage high-power silicon steel core medium frequency transformer. IEEE Trans. Ind. Electron. 2017, 64, 4391-4401. [CrossRef]

4. Bahmani, M.A.; Thiringer, T.; Kharezy, M. Design methodology and optimization of a medium-frequency transformer for high-power DC-DC applications. IEEE Trans. Ind. Electron. 2016, 52, 4225-4233. [CrossRef]

5. Ozturk, S.; Canver, M.; Cadirci, I.; Ermis, M. All SiC grid-connected PV supply with HF link MPPT converter: System design methodology and development of a $20 \mathrm{kHz}, 25 \mathrm{kVA}$ prototype. Electronics 2018, 7, 85. [CrossRef]

6. Harischandrappa, N.; Bhat, A.K. A $10 \mathrm{~kW}$ ZVS integrated boost dual three-phase bridge DC-DC resonant converter for a linear generator-based wave-energy system: Design and simulation. Electronics 2019, 8, 115. [CrossRef]

7. Kenzelmann, S.; Rufer, A.; Dujin, D.; Canales, F.; Romulo, Y. Isolated DC/DC structure based on modular multilevel converter. IEEE Trans. Power Electron. 2015, 30, 89-98. [CrossRef]

8. Schmidt, S.; Richter, M.; Oberrath, J.; Mercorelli, P. Control Oriented Modeling of DCDC Converters. IFAC PapersOnLine 2018, 51, 331-336. [CrossRef]

9. Peelaers, H.; Steiauf, D.; Varley, J.B.; Janotti, A.; Van De Walle, C.G. (InxGa1-x)2O3 Alloys for Transparent Electronics. Phys. Rev. B Condens. Matter Mater. Phys. 2015, 92, 1-6. [CrossRef]

10. Liu, X.; Tan, C.-K. First-Principle Investigation of Monoclinic (Al x In y Ga 1-x-y) 2 O 3 Quaternary Alloys. Semicond. Sci. Technol. 2020, 35, 025023. [CrossRef]

11. Liu, X.; Tan, C.K. Structural and Electronic Properties of Dilute-Selenide Gallium Oxide. AIP Adv. 2019, 9, 125204. [CrossRef]

12. Peart, M.R.; Tansu, N.; Wierer, J.J. AlInN for Vertical Power Electronic Devices. IEEE Trans. Electron. Devices 2018, 65, 4276-4281. [CrossRef]

13. Wei, Q.; Wu, B.; Xu, D.; Zargari, N.R. A medium-frequency transformer-based wind energy conversion system used for current-source converter-based offshore wind farm. IEEE Trans. Power Electron. 2017, 32, 248-259. [CrossRef]

14. Fan, H.; Li, H. High-frequency transformer isolated bidirectional DC-DC converter modules with high efficiency over wide load range for $20 \mathrm{kVA}$ solid-state transformer. IEEE Trans. Power Electron. 2011, 26, 3599-3608. [CrossRef]

15. Wang, Y.; Ni, F.; Lee, T. Hybrid modulation of bidirectional three-phase dual-active-bridge DC converters for electric vehicles. Energies 2016, 9, 492. [CrossRef]

16. Shuai, P.; Biela, J. Influence of material properties and geometric shape of magnetic cores on acoustic noise emission of medium frequency transformers. IEEE Trans. Power Electron. 2016, 32, 7916-7931. [CrossRef]

17. Huang, P.; Mao, C.; Wang, D. Electric field simulation and analysis for high voltage high power medium frequency transformer. Energies 2017, 10, 371. [CrossRef]

18. Sixdenier, F.; Morand, J.; Salvado, A.; Bergogne, D. Statistical study of Nanocrystalline alloy cut cores from two different manufacturers. IEEE Trans. Magn. 2014, 50, 1-4. [CrossRef]

19. Shen, W.; Wang, F.; Boroyevich, D.; Tipton, W. Loss characterization and calculation of Nanocrystalline cores for high-frequency magnetics applications. IEEE Trans. Power Electron. 2008, 23, 475-484. [CrossRef]

20. Ruiz, R.D.; Venegas, R.V.; Anaya, R.A.; Moreno, G.E.; Rodríguez, R.J. Design and prototyping medium-frequency transformers featuring a Nanocrystalline core for DC-DC converter. Energies 2018, 11, 2081. [CrossRef]

21. Krishnamoorthy, H.; Daniel, M.; Ramos, J.; Enjeti, P.; Liu, L.; Aeloiza, E. Isolated AC-DC converter using medium frequency transformer for off-shore wind turbine DC collection grid. IEEE Trans. Ind. Electron. 2017, 64, 8939-8947. [CrossRef]

22. Ruiz, R.D.; Ortíz, M.J.; Venegas, R.V.; Moreno, G.E.; Granados, L.D.; Rodríguez, R.J. Nanocrystalline and silicon steel medium-frequency transformer applied to DC-DC converters: Analysis and experimental comparison. Energies 2019, 12, 2062. [CrossRef]

23. Ohta, M.; Hasegawa, R.; Itabashi, H. Development of block cores comprising high-Bs Nanocrystalline alloy ribbon. IEEE Trans. Magn. 2018, 54, 2000504. [CrossRef] 
24. Kauder, T.; Hameyer, K. Performance factor comparison of Nanocrystalline, amorphous, and crystalline soft magnetic materials for medium-frequency applications. IEEE Trans. Magn. 2017, 53, 8401504. [CrossRef]

25. Soltau, N.; Eggers, D.; Hameyer, K.; Doncker, R. Iron losses in a medium-frequency transformer operated in a high-power dc-dc converter. IEEE Trans. Magn. 2014, 50, 7023604. [CrossRef]

(C) 2020 by the authors. Licensee MDPI, Basel, Switzerland. This article is an open access article distributed under the terms and conditions of the Creative Commons Attribution (CC BY) license (http://creativecommons.org/licenses/by/4.0/). 